\title{
EL CASO DEL REACTIVO PRECIPITADO POR LA HEMOGLOBINA: LA NOVELA POLICIACA Y SUS (DES)ENCUENTROS CON LA CIENCIA
}

\section{THE RE-AGENT PRECIPITATED BY HAEMOGLOBIN AFFAIR: THE DETECTIVE NOVEL AND ITS ENCOUNTERS WITH SCIENCE}

\author{
Manuel GONZÁLEZ DE LA ALEJA BARBERÁN \\ Universidad de Salamanca \\ mgonzalez@usal.es
}

Resumen: Desde sus comienzos, la novela policíaca ha hecho uso del mundo de la ciencia como parte de sus argumentos. Este artículo pretende ilustrar los casos más significativos en que ciencia y novela policial se han dado la mano a lo largo de la historia del género.

Abstract: Since its birth, detective fiction has used science as part of its plots. This article intends to highlight the most significant cases where science and crime fiction have walked hand in hand throughout the history of the genre.

Palabras clave: Literatura. Ciencia. Género Popular. Novela Policíaca.

Key words: Literature. Science. Popular Genre. Crime Novel. 


\section{UN GÉNERO Y TRES INSTANTES}

En la retina de todo buen aficionado a la literatura policíaca están congelados tres momentos fundacionales del género. El primero, tuvo lugar en 1841 cuando un incomprensible crimen fue cometido en un edificio en la calle Morgue de París. El segundo, se produjo algunos años más tarde, exactamente en 1887, y recrea el encuentro en un hospital londinense de dos hombres que llegarían a convertirse en compañeros de piso y grandes amigos. El tercero, se sitúa en el pasado siglo, en 1939, cuando un detective privado, alto y fornido, se dispone a entrar en la lujosa mansión de los Sternwood, en las afueras de Los Ángeles. Estos tres momentos marcan la esencia genérica de la novela de detectives y apuntan a los distintos caminos que va a seguir a lo largo de su universo geográfico y temporal. Además, también nos sirven para demarcar la turbulenta relación que, a veces, este tipo de narrativa va a tener con el mundo de la ciencia.

Cuando Edgar Allan Poe publica sus «Murders in the Rue Morgue» («Los crímenes de la calle Morgue») ofrece a la posteridad dos firmes piedras angulares sobre las que se sustentará el edificio del genero policial. Por una parte, el misterio más complicado de esclarecer, el horrible crimen cometido en una habitación cerrada en la que nada ni nadie ha podido entrar y de la que nada ni nadie ha podido tampoco salir. Por otra parte, la mente extraordinaria de un detective capaz de averiguar lo que realmente ha sucedido entre esas cuatro paredes. Para la solución del enigma Poe dota a su héroe de un arma llamada «método analítico», de forma que el terrible crimen cometido y su investigación quedan planteados como un mero entretenimiento, similar al ajedrez, las damas o algunos juegos de naipes, donde una serie de facultades mentales han de ponerse en práctica. El autor de la historia, a través de su narrador, nos explica que el análisis va más allá del mero cálculo matemático o de un simple ejercicio de memoria; consiste ante todo en «la calidad de la observación», saber «lo que se debe observar»e inferir de esa observación las conclusiones precisas. Por supuesto, Monsieur C. Auguste Dupin alcanza el pleno virtuosismo en este sentido, no tan solo por la resolución de lo acaecido en el número 13 de la calle Morgue, sino también por algunos ejemplos de su excelencia deductiva algo menos celebrados. Recordemos, por ejemplo, cómo Dupin es incluso capaz de saber lo que su compañero de piso, y narrador de sus andanzas, está pensando en un momento determinado (Poe, 1959: 11).

No obstante, A Study in Scarlet (Estudio en escarlata) es, sin lugar a dudas, el gran inicio del género. En esta primera obra de la legendaria saga 
del detective Sherlock Holmes nos encontramos por primera vez con un médico militar llamado Watson que, recién llegado a Londres, busca compartir piso con la persona adecuada. Un viejo conocido le habla de otro caballero inglés, «entusiasta de algunas ramas de la ciencia», «versado en anatomía» y «químico de primera clase», pero que «no ha asistido sistemáticamente a ningún curso de medicina», que se halla en una tesitura parecida a la suya. Pese a que a Watson se le advierte de que el tal Holmes posee «un carácter demasiado científico» y que en la sala de disección aporrea los cadáveres con su bastón «a fin de ver hasta qué punto pueden producirse magulladuras en un cuerpo muerto» ${ }^{1}$, el médico decide probar suerte y conocer a tan estrafalario personaje. El encuentro tiene lugar en la sala del laboratorio de un gran hospital, «llena toda de frascos que se alineaban a lo largo de las paredes o yacían desperdigados por el suelo» y «unas mesas bajas y anchas erizadas de retortas, tubos de ensayo y pequeñas lámparas Bunsen con su azul y ondulante lengua de fuego». Las primeras palabras que Holmes va a pronunciar en esta sala para Watson y toda la posteridad son: «iLo he encontrado! ¡Lo he encontrado!... He hallado un reactivo que precipita con la hemoglobina y solamente con ella». Para asombro de Watson, y sus serias dudas sobre la utilidad del experimento, Holmes añade una gota de su propia sangre a un litro de agua, la cual lógicamente no modifica su apariencia hasta que el detective «arrojó en el recipiente unos pocos cristales blancos, agregando luego algunas gotas de cierto líquido transparente». En ese momento es cuando la mezcla cobra un «opaco color caoba» (Conan Doyle, 2009: 18-19, 20-23) , que resume esa gran contribución a la medicina legal que tanto entusiasma al inminente compañero de Watson. Así pues, desde el principio de sus longevas andanzas, el detective creado por Sir Arthur

\footnotetext{
1 En la, de momento, última revisión catódica del mito del detective, la serie Elementary (Robert Doherty, 2012) hay un curioso homenaje a esta peculiar afición de Holmes. En el comienzo del quinto capítulo, titulado «Lesser Evils» («Mal menor»), el detective se encuentra en un depósito de cadáveres estrangulando con las manos o con el brazo los cuerpos sin vida allí presentes. Como explica a la estoica, ahora doctora, Joan Watson, está estudiando las marcas que una muerte por estrangulamiento puede dejar en las víctimas.

2 En la edición anotada por Leslie S. Klinger de las cuatro novelas protagonizadas por Holmes existe una interesante información sobre la validez del experimento llevado a cabo por el detective. Algunos autores citados por Klinger como Remsen Eyck Schenk consideran sin fundamento que «solo» la hemoglobina pudo precipitar el agente. Por el contrario, Leon S. Holstein sugiere que esta primera prueba llevada a cabo por el legendario detective «fue una primera versión del examen hemocromógeno utilizado para identificar manchas de sangre». Y por su parte Christine L. Huber «identifica la prueba como una de las tantas 'redescubiertas' en la década de 1930, cuando se descubrió que la hemoglobina A es desnaturalizada por el hidróxido de sodio ('cristales blancos') y después precipitada con sulfato de amonio saturado ('el líquido transparente')» (Conan Doyle, 2009: 22).
} 
Conan Doyle se nos aparece como un hombre de ciencia, aunque solo interesado en su vertiente más práctica como auxiliar en la resolución de crímenes.

Pero el mítico encuentro entre el doctor Watson y Sherlock Holmes es rico también en otros indicios sobre la personalidad y el talante investigador del segundo.

Por una parte, en la tradición del detective de Edgar Allan Poe, Holmes cultiva la «ciencia de la deducción». El ejemplo nos lo brinda ese comentario en apariencia inocente que le hace al doctor nada más conocerlo: «por lo que veo, ha estado usted en tierras afganas» (Conan Doyle, 2009: 20). El asombro de Watson ante este comentario será uno de los elementos característicos de la saga. Una y otra vez el doctor, y nosotros junto a él, tendrá que esperar a que el detective tenga a bien desvelar el proceso de razonamiento que le ha hecho llegar a sus sorprendentes y aceradas conclusiones. Sherlock Holmes lleva así al virtuosismo el método detectivesco que Dupin había comenzado en París. Tan es así, que tanto la cultura popular en general como la narrativa policíaca en particular están plagadas de máximas y ejemplos que ilustran la capacidad deductiva del legendario investigador. Es en El signo de los cuatro donde Holmes pronuncia la famosa frase: «una vez eliminado lo imposible, la verdad está en lo que queda, sin importar cuán improbable parezca» (Conan Doyle, 2009: 274).

Será en The Big Sleep (El sueño eterno), la obra de Raymond Chandler, cuando una nueva novela policíaca, con la inestimable ayuda de sus adaptaciones cinematográficas, dote de una renovada energía al género y fije las pautas que habrá de seguir durante años. Es cierto que antes de la llegada de Philip Marlowe a la mansión de los Sternwood una nueva casta de detectives ya se había dado a conocer, y que es el propio Chandler el que otorga a Dashiell Hammett el título de «padre» de esa nueva criatura llamada novela «hard-boiled». Pero en esta búsqueda en la que nos vemos enfrascados de los momentos indelebles de lo policíaco, los primeros párrafos de $E l$ sueño eterno han de figurar con honores. En ellos nos encontramos a un detective «aseado, limpio, afeitado y sereno y no me importaba que se notase» a punto de encontrarse con su cliente:

El recibidor del chalet de los Sternwood tenía dos pisos. Encima de las puertas de entrada, capaz de permitir el paso de un rebaño de elefantes indios, había un vitral en el que figuraba un caballero con armadura antigua rescatando una dama que se hallaba atada a un árbol, sin más encima que una larga y muy oportuna cabellera. Tenía levantada la visera de su casco, 
como muestra de sociabilidad, y jugueteaba con las cuerdas que ataban a la dama, al parecer sin resultado alguno. Me detuve un momento y pensé que de vivir yo en esta casa, tarde o temprano tendría que subir allí y ayudarle, ya que parecía que él, realmente, no lo intentaba (Chandler, 2009: 6).

Frente al detective que había imperado desde la aparición de Sherlock Holmes, cuyas virtudes se basaban en una mente analítica enfrentada a puzzles criminales tan enrevesados como inocuos, aquí nos encontramos con un detective profesional de un fuerte carácter independiente que se considera a sí mismo no tanto una máquina de pensar como un caballero andante en una época en la que estos probablemente hayan dejado de tener un porte heroico. Del laboratorio de Holmes o del sillón de Dupin nos hemos trasladado a callejones malolientes y garitos ilegales donde la investigación es un ejercicio de entereza profesional por parte del detective.

Estos son los tres momentos fundacionales del género. En ellos se resumen las cualidades que han hecho de la novela policíaca una de las favoritas del público a lo largo y ancho de décadas y países. Y cada uno de ellos nos da pie a rastrear sus (des)encuentros con lo científico.

\section{DE VIDOCQ A LECOQ}

Aunque hayamos situado el nacimiento de la novela policíaca en la calle Morgue y en los asesinatos que allí investigó Auguste C. Dupin, es el propio detective el que en este su primer caso menciona a un personaje al que cualquier artículo sobre crimen y ciencia debe hacer referencia: Eugène François Vidocq.

Gran parte de la información que nos ha llegado sobre este curioso personaje precede de sus Memorias, publicadas en 1828. En la primera parte, se nos cuenta que fue ladrón, contrabandista y estafador, actividades por las que fue a dar con sus huesos en la cárcel. Y es a partir de este momento en el que empieza una segunda vida en la que, primero, purga sus penas como confidente de la policía para a continuación no solo convertirse en uno de ellos sino llegar a fundar en París, y dirigir, durante dieciséis años, la Brigade de Sûreté, que más tarde se convertiría en la Sûreté Nationale. Es en esta actividad y en su labor como detective privado (se le acredita como creador en 1833 de la primera agencia privada de detectives que se conoce) en las que Vidocq cobra especial relevancia en el tema que nos ocupa. Su eficacia como policía y detective no solo se debió a su profundo conocimiento del mundo criminal, sino también a la brillante aplicación de métodos científi- 
cos a la actividad policial. Claro testimonio de ello nos lo ofrece un curioso y selecto club de investigadores y aficionados llamado «Vidocq Society». Fundada en 1990, en Filadelfia, con el propósito de esclarecer casos de muertes y, en ocasiones, desapariciones, no resueltos por las fuerzas policiales, la «Sociedad» rinde homenaje en su página web (http://www.vidocq. org/) al «padre de la investigación criminal moderna, Monsieur Vidocq» y a sus logros a favor de la justicia y la criminalística gracias a sus avances en la «creación de ficheros indexados», su maestría en el uso «del disfraz y la vigilancia» y sus descubrimientos en «balística», «moldes de huellas de pisadas», «tinta indeleble»y «papel inalterable».

Para pertenecer a esta exclusiva sociedad, compuesta únicamente por 82 miembros - uno por cada año de vida de Vidocq — es necesaria una amplia experiencia policial o forense. No es de extrañar, pues, que el currículum de muchos de sus componentes sea impresionante. Entre ellos se encuentran: un experto en «reconstrucción forense», especializado en reproducir para la policía caras a partir de los restos totales o parciales de cráneos humanos; un científico especializado en «supervivencia en casos extremos» de calor, frío, altitud, hipoxia, hiperoxia o inmersión, entre otros; el director de la «Academy for Scientific Investigative Training - An American Polygraph Association»; un «examinador forense de documentos», «reinserción en máquina de escribir» ${ }^{3}$ y diferenciación de tinta y papel; un especialista en el análisis de patrones de sangre y en la reconstrucción de «escenas del crimen»... En resumen, el reparto ideal para un episodio estelar de C.S.I., ya sea Las Vegas, Miami o Nueva York.

No obstante, la «Sociedad Vidocq» es fruto del siglo XX y si volvemos al legado literario del personaje real podemos observar que en un primer momento fue limitado. Tras los logros del policía francés y la obra fundacional de Poe, otros intereses narrativos, más allá de la pura investigación, van a dictar los relatos criminales de la época. Así, por ejemplo, en Bleak House (Casa desolada) (1851-53) de Charles Dickens vamos a encontrar un policía y una cierta investigación policial, pero el interés del autor se orienta más hacia la fábula social que hacia la resolución del enigma. De forma análoga, en Sheridan Le Fanu podemos rastrear ecos de ese «misterio de la habitación cerrada» ideado por Poe, pero será la fascinación gótica con su doncellas en peligro y sus villanos maléficos los que prevalezcan sobre el

3 En inglés recibe el nombre de «typewriter reinsertion» y se refiere a la habilidad para descubrir si alguien ha vuelto a reinsertar en la máquina de escribir un documento ya escrito previamente para añadir una palabra o un párrafo con el mínimo rastro de desalineación vertical u horizontal. 
«enigma puro» que va a caracterizar más adelante la «época dorada de la historias de detectives».

Un buen ejemplo de ello es la obra de Wilkie Collins, The Moonstone, publicada en 1868 y considerada tradicionalmente «la primera novela de detectives escrita en Inglaterra». En ella encontramos muchos de los patrones que luego se harán tan populares. Una mansión con un número de sospechosos limitado al listado de invitados a una fiesta de cumpleaños, el robo de un diamante que luego se condimentará con algo de secuestro, suicidio y asesinato y la llegada al lugar de los hechos de un detective tan peculiar como inteligente, el Sargento Cuff. Con todo, la investigación del caso se ve continuamente obstaculizada por los componentes de romance y sentimentalismo, y la resolución es demasiado increíble para resultar efectiva. Que el héroe, el elegido por el corazón de la heroína, sea el culpable inocente al haber sido intoxicado por opio y haber acudido inconscientemente a la habitación donde se hallaba el diamante y haberlo robado también inconscientemente, que esto se averigüe un año más tarde volviendo a drogar con opio al sospechoso y que este repita inconscientemente los actos que le llevaron al robo involuntario, nos aleja del propósito científico de estas páginas.

Durante los años que van desde Edgar Allan Poe hasta la aparición de la primera obra protagonizada por Sherlock Holmes las historias de detectives se debaten claramente entre el interés por la investigación policíaca en sí y los elementos románticos y sensacionalistas característicos de la literatura de la época. En autores como Israel Zangwill o Anna Katharine Green hay crímenes, un astuto detective y la consiguiente investigación, pero esta se ve contaminada continuamente por amores imposibles, historias de celos, casualidades, sueños o alucinaciones.

Esta última autora merece, no obstante, un lugar destacado en la tradición literaria detectivesca por haber creado uno de los misterios, o mejor, uno de los asesinatos, que más han dado que hablar en la tradición policíaca. En el comienzo de Initials Only (1911) una rica y bella heredera, completamente sana y llena de vida, cae fulminada en medio de una fiesta mientras se encuentra de pie y sola en un extremo de la sala. Todo apunta a una muerte súbita debida a alguna insospechada enfermedad. Pero un estudio más detenido del cuerpo de la muchacha descubre que entre el rojo de las hojas de flor de pascua que adornan la parte frontal de su vestido también se encuentra el rojo de la sangre que mana de una herida. La joven ha sido asesinada. La investigación que sigue se centra tanto en los posibles motivos del asesino como en torno al misterio del arma utilizada. No hay rastro de lo 
que pudo causar la fatal herida. Nadie se acercó a la muchacha en el momento de su muerte, por lo que el uso de un arma blanca queda descartado. La profundidad de la penetración de la herida denota, además, una fuerza inusitada para un ser humano. Al final de la novela, la confesión del asesino no solo aclara el misterio, sino que abre una pequeña leyenda dentro del género. Aprovechando el ruido de la banda de música, el amante despechado disparó sobre la víctima desde el otro extremo de la habitación; la bala, sin embargo, no era convencional: se trataba de un pequeño carámbano de hielo, con fuerza suficiente para entrar en el cuerpo de la víctima, pero imposible de rastrear una vez derretido. En definitiva, de la mano de su creadora, el asesino había encontrado el arma perfecta, la bala de hielo. Por desgracia, para los asesinos que quieran serlo, una bala de hielo parece no ser factible como instrumento para matar a un ser humano. No solo nos lo ha confirmado el programa de Discovery Channel MythBusters ${ }^{4}$ (Cazadores de mitos), también nos lo ha explicado muy claro el personaje Jack Hodgins en el capítulo 15 de la octava temporada de la serie Bones, «The Shot in the Dark» («Un disparo en la oscuridad»):

Primero: el calor que se genera en la ignición de la pólvora funde la bala de hielo antes de que salga del cañón.

Segundo: una bala de hielo tiene solo un tercio de la densidad del plomo. Para que el hielo penetre tiene que moverse al menos tres veces más rápido que una bala de plomo.

Por suerte, y para que nuestra imaginación no se quede huérfana, Hodgins nos propone un sustituto para el arma perfecta, la bala de sangre; una bala con los glóbulos rojos de la sangre centrifugados y congelados con nitrógeno líquido de forma que permanezcan estables.

Entre toda esta literatura sensacionalista muy divertida, pero nada científica, sí encontramos un digno heredero de Dupin y, sobre todo, del ínclito Vidocq. Nos estamos refiriendo, por supuesto, al escritor Émile Gaboriau y a su personaje Monsieur Lecoq. En las obras protagonizadas por este policía francés se retoma, siguiendo la tradición de Poe, la minuciosa inspección del lugar del crimen. Por ejemplo, en uno de sus casos es capaz de concluir, para sorpresa de sus superiores, que el uniforme militar de una de las vícti-

4 Gracias al programa sabemos que una bala de carne o de gelatina también son demasiado frágiles para causar un daño mortal. Eso sí, se puede disparar una cápsula de veneno desde un paraguas como ocurrió en el caso del asesinato del disidente búlgaro, Georgi Markov. 
mas es tan solo un disfraz, ya que su corte de pelo incumple claramente el reglamento. También unas huellas en la nieve le permiten sospechar que dos mujeres, una joven, en concreto una dama atractiva a juzgar por el tamaño y delicadeza de la pisada, y otra de mayor edad, han podido ser la causa de los trágicos acontecimientos acaecidos en una taberna unos minutos antes. Y de la misma manera, una precisa inspección ocular del césped le permite afirmar que fue el cuerpo de una mujer, la condesa, totalmente vestida con pesadas faldas, y no el del conde el que había sido arrastrado por el asesino en el escenario del crimen.

Si algo siempre se ha halagado de este miembro de las fuerzas de seguridad francesas ha sido lo avanzado de sus métodos policiales. No pocas antologías del género reflejan otro momento de Monseiur Lecoq (1868), en el que el protagonista hace uso de su inteligencia y capacidad de improvisación. De nuevo, nos encontramos al policía francés inspeccionando el lugar del crimen, en este caso junto a un veterano compañero. Su paciencia y empeño tienen recompensa al encontrar unas huellas de pisadas que les pueden conducir hasta el sospechoso o sospechosos. No obstante, el mal tiempo amenaza con hacer desaparecer el preciado rastro en unos instantes. El veterano agente ha oído de un método para conseguir el molde de una pisada que consiste en coger algo de gelatina, empaparla en agua, calentar la mezcla hasta que forma un líquido con algo de consistencia, dejarla enfriar y verterla sobre la huella. Lecoq, por supuesto, conoce ese método, está en todos los manuales, pero en esos momentos de urgencia le sirve de bien poco. Incansable al desaliento, el joven policía entra en una caseta cercana y crea todo el material para el molde con unas viejas cajas de cartón, un poco de agua y el polvo de escayola extraído, con una botella rota, de las paredes de la caseta:

Una vez en el jardín, el joven buscó la más profunda y clara de las huellas, se arrodilló a su lado, y empezó su experimento, temblando de ansiedad. Primero espolvoreó sobre la huella una fina capa de escayola seca, y después, sobre esta capa, vertió, con infinito cuidado y gota a gota su solución líquida ${ }^{5}$.

${ }^{5}$ No ha sido posible encontrar una edición en español de la obra de Gaboriau. La cita es mi traducción de la versión en inglés en formato electrónico: http://es.feedbooks.com/book/3729/monsieur$\operatorname{lecoq}(38)$. 
Tan rudimentario pero ingenioso procedimiento permite a Lecoq sacar varios moldes de las huellas y así seguir con óptimas garantías de éxito su investigación.

Estas pesquisas de Lecoq en el lugar de los hechos y el uso de las huellas de pisadas como instrumento de deducción sin duda debieron de servir de inspiración al propio Holmes. Ya en su primera novela, Estudio en escarlata, da muestras de su habilidad:

Se ha cometido un asesinato, y el perpetrador es un hombre. Mide más de seis pies, se halla en la flor de la vida, tiene pies demasiado pequeños para su altura, calza botas rudas de punta cuadrada y fuma cigarros tipo Trichinopoly ${ }^{6}$. Llegó aquí con la víctima en un cabriolé de cuatro ruedas, conducido por un caballo con tres herraduras viejas y una nueva en su pata delantera derecha. Con toda probabilidad, el hombre tiene el rostro rojo y las uñas de los dedos de su mano derecha son muy largas (Conan Doyle, 2009: 64).

En The Sign of Four (El signo de los cuatro), las huellas de unas extrañas pisadas serán fundamentales para esclarecer los hechos. Es en esta novela donde el propio detective afirma haber escrito toda una monografía sobre «cómo rastrear pisadas, con algunos comentarios sobre el uso de yeso en París para preservar las huellas» (Conan Doyle, 2009: 220), siendo estas referencias a París y el yeso un más que probable homenaje a sus colegas Vidocq y Lecoq.

\section{HOLMES Y LAS EDADES DE ORO}

La irrupción de Holmes en el mundo de la novela policíaca lo va a cambiar todo. Los hallazgos aislados de autores anteriores o el interés marginal de otros novelistas por la investigación se concretan en la obra de Conan Doyle en una generosidad y meticulosidad narrativa que van de la mano de la propia obsesión de su personaje por todo aquello que pueda facilitar la resolución del crimen. Sherlock Holmes puede convertirse así en el detective total. En él encontramos tanto el arte de la deducción típico de Dupin, como el componente emocional y sensacionalista de la trama, propio de

6 Recordemos que según ha afirmado el propio Holmes, en El signo de los cuatro, él mismo ha publicado un manual titulado: «Sobre las diferencias entre las cenizas de varios tipos de tabaco» (Conan Doyle, 2009: 219). 
Collins, y, por supuesto, ese interés científico y práctico que hereda de maestros como Vicocq o Lecoq.

Efectivamente, ya hemos visto cómo la influencia del detective creado por Emile Gaboriau es evidente en esa primera inspección del lugar del crimen, en que la presencia del asesino todavía es visible para los ojos de un experto. Las pisadas en el barro, la nieve, la hierba o el polvo pueden determinar la altura, peso e incluso la edad del sospechoso, su extracción social, raza y, por supuesto, el tipo de calzado que utiliza. Pero Holmes añade además a sus aventuras una técnica de investigación muy novedosa, la identificación de huellas dactilares como prueba (casi) inequívoca de la autoría de un crimen.

En el mundo real, el primer método para la identificación de sospechosos se basaba en la antropometría y es conocido como el «Bertillonaje» o «Bertillonage», llamado así por Alphonse Bertillon. Este policía francés desarrolló a partir de 1884 un sistema de fichas policiales que incluían fotografías de los sospechosos, los datos sobre las mediciones detalladas de las distintas partes de su cuerpo y el registro minucioso de sus marcas corporales, cicatrices o tatuajes. Su método quedaría paulatinamente desbancado ante los logros del policía argentino Juan Vucetich, el cual, aprovechando los estudios científicos del antropólogo inglés Francis Galton, adoptaría ya en 1891 el registro de huellas dactilares para la identificación de individuos. Este nuevo sistema dactiloscópico viajaría a Gran Bretaña de la mano de Sir Edward Richard Henry, que, a partir de julio de 1901, creó para el Scotland Yard un sistema de clasificación y rastreo de huellas dactilares para poder ser contrastadas entre sí.

Sir Arthur Conan Doyle y Holmes parecían estar muy atentos a estos avances policiales. En algunos de sus casos ya aparecen las huellas dactilares como parte importante de la trama. Probablemente la historia en la que su presencia es más significativa es «El misterio de Lower Norwood» ${ }^{7}$, publicada en octubre de 1903, solo dos años más tarde de ese 1901 en que Scotland Yard crease su propio departamento destinado al registro de huellas. En el caso que nos ocupa, el aburrimiento que atenaza a Holmes es interrumpido por un joven que irrumpe en el 212b de Baker Street pidiendo socorro. La policía está a punto de arrestarle por un crimen del que se declara inocente, aunque todo parece incriminarle. La noche en que pareció per-

7 El título original en inglés es «The Adventure of the Norwood Builder». En español también se ha traducido como «La aventura del constructor de Norwood» o como «El constructor de Norwood». 
petrarse el asesinato, el cliente de Holmes se hallaba con la víctima en el lugar del crimen y en esa misma habitación la policía encontró posteriormente una caja fuerte abierta, señales de violencia, pequeñas manchas de sangre y un bastón de roble, también manchado de sangre, propiedad del sospechoso. El hallazgo de «restos carbonizados» entre las cenizas de un incendio, en apariencia provocado, en un pequeño almacén de madera en la parte trasera de la misma casa y el hecho de que el sospechoso figure como heredero en un testamento ese mismo día redactado por la víctima terminan por convencer al inspector de Scotland Yard Lestrade de que el caso no puede ser más claro. No obstante, pese a las numerosas evidencias y a que su propia inspección del lugar de los hechos no las contradice, Holmes tiene dudas. Sus sospechas están alimentadas en parte por su intuición y en parte por la forma en que ese testamento incriminatorio fue escrito. El análisis de la escritura por parte del detective así lo demuestra:

Este borrador ha sido escrito durante un viaje. Las partes claras en las estaciones, las confusas durante el trayecto y las ilegibles al pasar por las planchas giratorias. Considerando que la redacción del testamento ha durado todo un viaje y que el tren no se ha detenido en ninguna estación, resulta claro, de toda claridad, que dicho tren era un exprés y que el trayecto ha sido el que media entre Norwood y el London Bridge (Conan Doyle, 1908: 66-67).

Pese al pálpito del detective, la investigación prosigue inexorable en contra de los intereses del joven acusado. Más adelante, Lestrade llama a Holmes para mostrarle la evidencia definitiva. En el vestíbulo de la casa de la víctima, en la pared encalada, la policía ha encontrado una mancha de sangre, «la huella inconfundible de un dedo pulgar» que coincide con la «impresión en cera del pulgar derecho» del sospechoso. Lestrade concluye satisfecho: «Estará usted al corriente de que no existen dos huellas dactilares iguales». A lo que Holmes no tiene más remedio que contestar: «Algo de eso he oído decir» (Conan Doyle, 1908: 83). El tono irónico de estas palabras ya nos hace intuir que el caso está a punto de dar un vuelco. La evidencia de la huella dactilar parece palmaria, pero también resulta demasiado raro que Sherlock Holmes no hubiese visto tamaña pista en su experta inspección de la escena del crimen. Y este detalle y el hecho de que un pasillo de la casa fuera dos metros más corto que el del piso de abajo son lo único que necesita el detective para resolver el caso y salvar a su inocente cliente de la horca... 
El uso o el mal uso de la detección de las huellas dactilares al servicio de la medicina forense forma parte también de algunas de las historias del que probablemente sea el sucesor más directo de Sherlock Holmes. En 1907 R. Austin Freeman publica la novela The Red Thumb Mark (La huella roja) ${ }^{8}$ y en ella nace el Dr. John Evelyn Thorndyke ${ }^{9}$. Este nuevo detective está especialmente preparado para la medicina forense, ya que a su condición de hombre de leyes une la de ser doctor en medicina. Su despacho está dotado de un taller y un laboratorio equipados con los más sofisticados aparatos y artilugios para la investigación de huellas dactilares, restos de tejidos, ceniza de cigarro, análisis de sangre, pruebas fotográficas... En esta su primera historia, y como su título indica, es precisamente el hallazgo de una huella dactilar en el lugar del crimen lo que desencadena la trama y la investigación.

El comienzo de la novela de Freeman es muy parecido al de «El misterio de Lower Norwood». En el despacho del detective irrumpe un joven que está a punto de ser arrestado por un crimen que él insiste no haber cometido, pese a que todas las pruebas parecen incriminarle, sobre todo, el hallazgo de una mancha de sangre con su huella dactilar. De nuevo el detective se deja llevar por su intuición y la honesta apariencia del sospechoso, y se hace cargo de su defensa. El problema que se plantea al investigador y a sus lectores es el siguiente. Unos valiosos diamantes han desaparecido de una caja fuerte, esta no ha sido forzada y solo tres personas tenían acceso a las llaves, el dueño del local y sus dos sobrinos. Dentro de la caja la policía ha encontrado manchas de sangre y una de ellas es, además, una huella dactilar de un pulgar perfectamente impresa en uno de los documentos allí depositados que se corresponde con las de uno de los sobrinos, Reuben Hornby. Para Scotland Yard y los expertos de su «Departamento de huellas dactilares» el caso es evidente porque, como con sumo detalle se nos narra en la página 150 (Freeman, 2004), «la posibilidad de que la huella de un dedo de una persona sea exactamente igual que la huella de ese mismo dedo de otra persona es de una entre sesenta y cuatro mil millones». No obstante, Thorndyke

8 Actualmente es muy difícil encontrar un ejemplar en español de esta novela. Las citas utilizadas en este artículo han sido traducidas por mí de la versión electrónica en inglés.

9 En la magnífica edición anotada por Leslie S. Klinger de las cuatro novelas protagonizadas por Holmes, se nos llama la atención sobre el interés que el detective de Freeman también demuestra por la prueba de la hemoglobina que nos sirvió para conocer a su antecesor. Es en la historia de 1925, The Shadow of the Wolf, donde aparece una prueba que consistía en mezclar «la resina del guacayo, lignum vitae» con alcohol y agregarla al líquido que se va a examinar. Según Klinger, «la prueba fue ensayada por primera vez en 1861 por J. Van Deen, con leves modificaciones» (Conan Doyle, 2009: 23). 
es de una opinión distinta y afirma, que desde la «histórica» publicación de la monografía de Francis Galton ${ }^{10}$, la evidencia de las huellas dactilares se admite, equivocadamente, sin ningún tipo de corroboración, «como si fuera una piedra de toque mágica» que ahorrase a la policía la obligada labor de investigación (Freeman, 2004: 74). Para la defensa del infortunado joven y para los lectores, a estas alturas de la novela nosotros también creemos ciegamente en su inocencia, solo queda pues un camino, demostrar que una huella dactilar puede ser falsificada.

El desenlace de la novela se concentra en el juicio contra Reuben Hornby. El fiscal y los expertos de Scotland Yard presentan sus pruebas, informando de forma prolija al jurado sobre la ciencia de las huellas dactilares y su eficacia. Por su parte, la defensa de Thorndyke se centra en dos aspectos fundamentales: el análisis de la sangre encontrada dentro de la caja fuerte y el estudio de la famosa huella dactilar que incrimina a su defendido. En cuanto a la sangre, se presentan pruebas irrefutables, por parte de un experto en el estudio de las «propiedades de la sangre», de que es prácticamente imposible conseguir una huella dactilar clara con sangre fresca, ya que el líquido se extiende entre las crestas papilares, y, en consecuencia, hay que esperar a que ésta se seque para que deje una impresión fiable. En cuanto a la huella dactilar propiamente dicha, Thorndyke explica ante el jurado cómo se ha producido la falsificación:

En primer lugar es necesario obtener o tener acceso a una huella dactilar genuina. Se toma una fotografía, o mejor dicho, un negativo fotográfico, que para este propósito se debe tomar en una placa invertida, y el negativo se coloca en un bastidor, con una lámina de gelatina que ha sido tratada con bicromato de potasio, y se expone a la luz (Freeman, 2004: 163).

Dado que la «gelatina cromizada» solo es soluble en agua caliente si no se expone a la luz, a través de este proceso, solo las partes transparentes del negativo, las correspondientes a las crestas papilares, son afectadas por la luz y por lo tanto permanecen insolubles. Una vez que la placa se lava con agua, esas crestas que permanecen intactas de la copia crearán un facsímil de la huella original.

10 Galton ya había publicado un estudio sobre huellas dactilares en 1888 y, más adelante, escribiría tres libros sobre el tema: FingerPrints (1892), Decipherment of Blurred Finger Prints (1893) y Fingerprint Directories (1895). 
Una vez establecida la posibilidad de la falsificación, la defensa tiene todavía dos dudas que resolver. La primera, consiste en determinar cómo se consiguió la huella original; y la segunda, demostrar que, efectivamente, la prueba presentada por la acusación es una falsificación.

La respuesta a la primera pregunta nos habla de lo novedoso y curioso que el mundo de las huellas dactilares resultaba para esos personajes de principios del siglo XX. En esa época el llamado «Thumbograph», un librito donde recoger las huellas de los pulgares como entretenimiento de los invitados en las largas tardes de lluvia británicas, se convirtió en un juguete popular. En La huella roja ese libro cae en poder del sobrino malvado de la historia y le permite conseguir una copia de la huella del sobrino inocente. No obstante, el error del criminal, y así respondemos a la siguiente pregunta, es que la copia resulta demasiado perfecta y recoge no solo las particularidades irrepetibles de la huella original sino también las peculiaridades del papel de ese «Thumbograph» del que fue tomada.

Otro caso sobresale en la larga lista de éxitos del abogado Thorndyke. Nos referimos a «A Wastrel's Romance», aparecido en la colección The Singing Bone de 1912. En las primeras páginas de estas historia presenciamos el brutal asesinato cometido por un individuo llamado Baily. En su huida el criminal comete dos errores: toma el abrigo equivocado y deja el suyo con la llave de su apartamento en uno de los bolsillos. Para la policía estos dos objetos son totalmente inútiles, pero para el detective científico son suficientes para atrapar al asesino. En su sofisticado laboratorio, Thorndyke cuenta con un «extractor de polvo», algo parecido a un aspirador, pero con la particularidad de que el tubo permite introducir un pequeño portaobjetos de microscopio donde quedan depositadas las muestras que se van a analizar. Gracias a este aparato, el detective puede clasificar los restos más frecuentes en el abrigo y determinar en qué zona de Londres vive. En la muestra se halla almidón de arroz, almidón de trigo y especias. Dado que los restos son más frecuentes en el lado derecho del abrigo, cuando el presunto criminal sale de su casa por la mañana, y casi inexistentes en el lado izquierdo, cuando regresa a su domicilio y las fábricas ya han cerrado, hay que buscar una zona de la ciudad donde confluyan un molino de arroz, un molino de harina y una fábrica de especias. Solo en Dockhead se produce esa coincidencia. Acotada la zona, es solo cuestión de probar qué portal abre la llave encontrada en el bolsillo del abrigo delator. Como Gil Grissom, de C.S.I., diría muchos años 
más tarde, «Sí, las fibras en tus vaqueros demuestran que estuviste en Dream Dolls esa noche. Todo ha terminado, Tera $\gg^{11}$ (Collins, 2002: 294) ${ }^{12}$.

Lo que no había terminado, ni muchísimo menos, era la larga historia de la novela policíaca nacida al amparo de la larga sombra de Sherlock Holmes y sus aventuras. Las llamadas edades de oro del género aparecen repletas de los más variados y singulares detectives que de forma más o menos acertada emulan las proezas del personaje de Conan Doyle.

Podemos argumentar, no obstante, que, de la riqueza narrativa del antecesor, estas historias se quedan solo con un aspecto, el que denominamos el «relato de enigma puro». Todas las consideraciones argumentales, incluso los aspectos más románticos y sentimentales, se van dejando a un lado para que el acertijo, el «crucigrama» como lo ha llamado tan acertadamente Javier Coma (1982: 13), cobre un protagonismo absoluto. Frente a un misterio, normalmente un asesinato, totalmente desconcertante, los autores nos proponen competir, en un principio a través de las reglas del «fair-play» o juego limpio, contra la mente de un extraordinario investigador. Esta nueva vuelta de tuerca se sostiene sobre dos mecanismos fundamentales: la complejidad del crimen y las capacidades mentales del detective. Normalmente estas capacidades se refieren a sus habilidades meramente deductivas o analíticas, despojándole en la mayoría de los casos de toda la parafernalia científica y técnica en poder de Holmes o el doctor Thorndyke. El detective se convierte de esta manera en una perfecta «máquina de pensar». Así, por ejemplo, Jacques Futrelle titularía sus colecciones de relatos protagonizados por el detective Augustus S.F.X. Van Dusen, The Thinking Machine (1907) y The Thinking Machine on the Case (1908). En la misma línea, la Baronesa de Orczy publicó en 1909 los casos del The Old Man in the Corner («el viejo del rincón»), un detective de cráneo prominente, que pasa las tardes sentado en un rincón de una cafetería, y que, desde allí, sin nunca moverse y sin más instrumento que su propia mente y los datos que le facilitan los periódicos, sus clientes o la policía, resuelve los misterios más inexplicables ${ }^{13}$. Ernest

11 No obstante, como veremos más adelante, los adelantos de la ciencia forense también tienen sus límites. Miguel Orós, miembro de la Escuela Judicial de Barcelona, comenta con respecto a ficciones como la serie televisiva C.S.I.: «alrededor del $40 \%$ de las presentaciones de las científicas que aparecen en estas series no son posibles en la actualidad, y menos la presentación de resultados como 'lápiz de labios, color 82, serie B-600’» (Orós, 2008: 180).

12 Mi traducción del original en inglés.

13 En la historia «El misterio de Dublín», el detective deja claro ese concepto de juego de inteligencia tan típico de estas historias: «El crimen no me interesa más que cuando se parece a una partida de ajedrez, bien jugada, con muchos e intrincados movimientos de las piezas» (Orczy, 1960: 332). 
Bramah Smith privaría al protagonista de sus historias, Max Carrados, incluso del poder de la observación visual, ya que Carrados es ciego y solo es su privilegiada mente la que le permite tener éxito en sus casos.

De todos estos innumerables casos y detectives, dos extremos pueden resultar curiosos dentro del tema que nos ocupa.

El detective Craig Kennedy, creado por Arthur B. Reeve, es conocido, tal vez de forma un tanto exagerada, como «el Sherlock Holmes americano». El nombre probablemente se lo ganó por ser un detective eminentemente científico ${ }^{14}$. Al igual que Holmes o Thorndyke sus principales armas son su capacidad analítica pero también sus amplios conocimientos forenses. Una historia especialmente interesante en este sentido es la llamada «Spontaneous Combustion» de 1911. En ella, de nuevo, la plácida existencia del detective y su particular Watson y narrador se ve interrumpida por la llegada de un mensaje enviado con urgencia la noche anterior. Un antiguo compañero de universidad se encuentra en un grave apuro y la intervención de Kennedy se hace inmediatamente necesaria. Una vez los dos protagonistas se personan en la escena del crimen, esta resulta especialmente desconcertante. La víctima se encuentra tendida en el suelo del salón, su cabeza y su pecho han quedado reducidos a cenizas por el fuego, pero la parte inferior de su cuerpo aparece intacta y en la habitación no hay ningún indicio de incendio. Todo indica que es un caso típico de «combustión espontánea humana» o, como se la conoce en términos científicos, «catacausis ebriosus»:

La combustión parece ser repentina y aparentemente confinada a las cavidades-el abdomen, el pecho, y la cabeza. Las víctimas de accidentes con fuego se lanzan de un lado a otro de forma frenética, sucumben a la extenuación, sus miembros se queman, y su ropa queda totalmente destrozada. Pero en la catacausis, son fulminados sin previo aviso, los miembros raramente aparecen quemados, y solo la ropa en contacto con la cabeza y el pecho se consume... Se dice que arden con una llama azul parpadeante, y el agua, lejos de contrarrestar la combustión, parece alimentarla (Reeve, 1994: 427) ${ }^{15}$.

${ }^{14}$ En su edición de colección de relatos de la «época dorada de los detectives», Marie Smith comenta que gran parte de la información científica ofrecida por este autor «ha envejecido bastante mal» (Smith, 1994: 18). No obstante, en algunos casos esa información sí ilustra con bastante rigor las novedades de la época en ese campo. Un caso característico es la historia «The Silent Bullet», donde, en 1910, Reeve incluye como explicación a un misterioso asesinato lo que él llama «el artefacto del inventor de Hatford» que no es otro que el silenciador para pistola patentado solo dos años antes por Hiram Percy Maxim.

15 Mi traducción del original en inglés. 
Esta peculiar forma de muerte súbita es un viejo y recurrente misterio en las novelas de corte criminal. Ya aparecía en Bleak House (1851-1853) de Charles Dickens, donde el autor la utilizaba como método radical para acabar con la mezquindad de su malvado Krook ${ }^{16}$. Esta impactante muerte de Krook sirve también de arranque a la historia protagonizada por Craig Kennedy. Efectivamente, como la historia de Reeve ilustra de forma prolija, la investigación que ahora ocupa la sagacidad de su detective parece obedecer al patrón que la ciencia ha otorgado a ese extraño caso de muerte súbita. Pero, pese a lo determinante de los indicios, Craig Kennedy duda de que la ciencia pueda amparar la teoría de la «combustión espontánea», como ya determinaron los experimentos del «inmortal Liebig» ${ }^{17}$. El hecho de que el «setenta y cinco por ciento o más» del cuerpo humano sea agua hace que el tipo de combustión descrita en la catacausis sea imposible, al contrario de lo que «los expertos científicos del siglo pasado creían». No, la resolución del caso debe obedecer a una explicación más rigurosa y aquí, de nuevo, una mínima cantidad de sangre acude en ayuda del detective. La «prueba de la Precipitina», según los hallazgos del científico alemán Paul Uhlenhuth, que hace posible distinguir la sangre humana de la animal, y los conocimientos necesarios para determinar a qué altura ha de caer una gota de sangre para dejar cierto tipo de mancha en un superficie lisa permiten a Kennedy determinar que la víctima fue golpeada antes de que la mitad de su cuerpo fuera introducido en la chimenea encendida del salón.

Frente a los métodos científicos de Craig Kennedy, y al otro lado del espectro, encontramos, por supuesto, al entrañable Padre Brown.

Para finales de la segunda década del siglo XX, las historias de detectives se habían vuelto tan numerosas y variadas que algunos autores sintieron la necesidad de poner por escrito una serie de principios fundamentales que regulasen sus argumentos y estrategias narrativas. Así lo hicieron en 1928 S.S. Van Dine con su «Veinte reglas para escribir historias de detectives», la normativa del «The London Detection Club» y Ronald A. Knox con su «Decálogo para una historia de detectives».

16 Dickens fue duramente criticado por utilizar este recurso, considerado por muchos como una vieja superstición, lo que obligaría al autor a defenderse con vehemencia en posteriores ediciones, aportando en sus prefacios referencias inequívocas sobre la realidad científica de la «Combustión Espontánea Humana» en «unos 30 casos» contrastados en todo el mundo.

17 Kennedy se refiere al químico alemán, el barón Justus von Liebig (1803-1873), el fundador de la química agrícola. 
El club londinense fundado por Anthony Berkeley prohibía el uso de «la revelación divina», «la intuición femenina», «la coincidencia» $\mathrm{o}$ «un acto de Dios»; hacía prometer a sus candidatos observar moderación en el uso de «Gangs, Conspiraciones, Rayos Mortales, Fantasmas, Trampillas, Chinos, Super-Criminales y Lunáticos»; y les exigía «renunciar a Venenos Misteriosos desconocidos para la Ciencia» (Haycraft, 1974: 197).

Por su parte, Knox, además de incluir también la regla de que «ningún chino apareciese en la historia», que hacía extensiva a gemelos y dobles, abundaba sobre los límites que habían de adoptarse a la hora de explicar el misterio que envuelve al crimen. En este sentido, criticaba a varios autores en concreto. Por una parte, en su regla número IV, «No debe utilizarse ningún veneno todavía no descubierto, ni ningún instrumento que requiera una larga explicación científica al final», cuestiona a Freeman y su detective Thorndyke por convertir el juego de detección en una «larga conferencia científica». Por otra parte, en su regla número II, «Todos los agentes supernaturales o preternaturales deber eliminarse por costumbre», hace especial referencia a las historias del Padre Brown de Gilbert Keith Chesterton, acusándole de que desde el principio conoce la identidad del asesino gracias a una «misteriosa revelación» (Haycraft, 1974: 194).

Es cierto que el sacerdote católico Brown podría representar las antípodas de esa legión de detectives racionales que pueblan estos años dorados. No porque su condición de sacerdote le convierta en un «agente supernatural», Brown nunca afirma recibir información privilegiada de ninguna fuente divina, sino porque el concepto de razón pura suele aparecer como problemática en sus historias. En «La cruz azul», de El candor del Padre Brown, el detective predica que:

Ya sé que la gente acusa a la Iglesia de rebajar la razón; pero es al contrario. La Iglesia es lo único que, en la tierra, hace de la razón un objeto supremo; la única que afirma que Dios mismo está sujeto por la razón (Chesterton, 1939: 21) ${ }^{18}$.

Pero, por otra parte, en la historia de la misma colección «El jardín secreto» (Chesteron, 1939: 7), Aristides Valentín, jefe de la Policía de París, se nos presenta literalmente como «una máquina de pensar», un hombre de

18 De hecho en esta misma historia la perspicacia del sacerdote hace que desvela la identidad de un criminal disfrazado de religioso porque durante su conversación «usted atacó la razón; y eso es de mala teología» (Chesterton, 1939: 25). 
talante científico y ateo militante. Y es precisamente esa obsesión por la razón, y su odio por lo que él llama «la superstición de la Cruz» la que hará que se convierta en asesino y termine suicidándose.

Es lógico entender los recelos de Knox ante los métodos del personaje de Chesterton. En sus historias hay crimen y hay misterio, pero la detección, el análisis deductivo de los hechos, es apenas visible. El método de Brown se basa vagamente en la razón o el sentido común, pero, efectivamente y sobre todo, en una capacidad sobrehumana de ver en el interior del alma de hombres y mujeres, entendiendo las debilidades e impulsos del sospechoso en cuestión.

\section{TIPOS DUROS, ACTORES DE REPARTO Y PROFESIONALES}

Alrededor de 1922 un soplo de aire fresco empieza a recorrer las estancias de la novela criminal. Es en Estados Unidos y, sobre todo, a través de los «pulps» capitaneados por Black Mask donde las historias de detectives sufren un cambio importante y bastante revitalizador. Es en esos años cuando Carroll John Daly presenta al mundo una nueva especie de detective, llamado Race Williams o Terry Mack, con el que realmente es muy difícil comparar a la multitud de colegas que le habían precedido. Frente a esas «máquinas pensadoras», este nuevo personaje prefería actuar a pensar, golpear a deducir, y disparar a preguntar. Coraje, fuerza física, un lenguaje agudo e irónico, y rapidez con la pistola son las armas típicas de un detective que se sitúa a sí mismo en el centro de un triángulo formado por el criminal, la policía y la víctima. Es el propio Raymond Chandler el que, en «The Simple Art of Murder» («El simple arte de matar»), tácitamente inscribe sus libros y los del maestro Hammett en la tradición clásica de la novela de detectives para reivindicar el deseo de ruptura que ellos se plantearon. Una ruptura que podemos entender en los siguientes términos.

En la fórmula clásica, el asesinato es cometido por brillantes mentes criminales que desafían la inteligencia del detective. En las obras de Hammett o Chandler, el crimen ya no es una de las bellas artes, sino algo más bien brutal y muchas veces torpe, cometido por gente estúpida o sin escrúpulos. El crimen pasa de ser un fenómeno aislado que puede diseccionarse tranquilamente en un laboratorio a convertirse en una especie de epidemia que alcanza cada rincón de la tortuosa alma humana. Si Holmes podía asomarse a la calle y lamentarse de lo aburrida que resulta una sociedad apenas sin crímenes ni criminales, este solitario detective privado se verá envuelto 
nada más franquear la puerta de su oficina en un mundo corrupto y violento donde nadie está limpio de mancha. En la fórmula clásica, la sospecha recae sobre todos los personajes para que al final sepamos que solo uno de ellos ha sido el culpable y podamos respirar tranquilos sabiendo que el orden y el equilibrio social han sido restablecidos. En la nueva fórmula todos los personajes son de alguna forma responsables del crimen por ejecución, inducción o encubrimiento.

En este contexto, de poco van a servir al detective su capacidad analítica o sofisticados recursos forenses. Serán su instinto y su inocencia naturales, todavía no corrompidos por el entorno social, los que le permitan sobrevivir en ese entorno hostil. Las instituciones, las leyes, la ciencia, la tecnología no son los aliados de la justicia, sino los enemigos reales del héroe y, por lo tanto, de la humanidad. El individuo se ve atrapado y aniquilado por un sistema social avalado por las creaciones de la ciencia y la tecnología. Dos imágenes cinematográficas de dos clásicos del género nos pueden ayudar a entender esta idea.

En 1955, Robert Aldrich dirigió una peculiar adaptación de las novelas protagonizadas por el detective creado por Mikey Spillane, Mike Hammer. Kiss Me Deadly (El beso mortal) sigue en un principio las pautas del género. Como en El halcón maltés, encontramos de nuevo un detective duro y expeditivo en busca de un objeto, una extraña caja, por la que todo el mundo está dispuesto a engañar, traicionar, seducir, torturar o matar. El gran enemigo de Hammer se convierte en el artífice del misterioso contenido de esa caja, un científico llamado Dr. Soberin. Por supuesto, y siguiendo las reglas de la fórmula, el héroe se deshace de los villanos, seduce a la femme fatale y encuentra el misterioso objeto. No obstante, cuando la caja se abre su peligroso contenido se muestra con toda su fuerza, la explosión que rubrica el final de la película es prueba de las devastadoras consecuencias a las que la ciencia y la ambición humana nos han abocado.

En 1982, Ridley Scott llevó a las pantallas una versión muy libre de la obra de Philip K. Dick, ¿Sueñan los androides con ovejas eléctricas? Las poderosas imágenes de Blade Runner nos muestran un mundo absolutamente controlado por la ciencia y la tecnología, hasta tal punto que el ser humano tiene problemas para determinar qué es humano y qué es artificial. Rick Deckard, el nuevo detective, es contratado para dar caza a un grupo de replicantes, robots creados a imagen y semejanza de los humanos, salidos del gran emporio comercial Tyrell Corporation. La nueva búsqueda del héroe se lleva a cabo a través de una ciudad asfixiante y caótica donde los restos de 
humanidad serán cada vez más difíciles de detectar y donde el propio detective habrá de dudar de su propia naturaleza y origen. La única opción que el guion va a ofrecer al detective no será tan destructiva como la que nos muestra la película de Aldrich pero sí bastante incierta. La ciudad es dejada atrás y una hipotética y exuberante frontera parece ofrecer al héroe un nuevo comienzo, contando, claro está, con que ni él mismo ni la mujer que ama sean también productos con fechas de caducidad elaborados por una gran corporación.

Blade Runner resume todas las características de esa ficción policíaca nacida en Estados Unidos en las primeras décadas del siglo XX y, en muchos sentidos, logra llevar al límite genérico muchos de los elementos de la fórmula. La voz narradora en primera persona, la gabardina del héroe, el vestido ceñido de la vampiresa, los intimidantes edificios de la gran ciudad recrean los lugares comunes de un género que, con el tiempo, ha necesitado reinventarse para garantizar su supervivencia.

Si los autores norteamericanos lograron dotar de una nueva energía a la novela criminal en el siglo pasado, es a partir de finales de ese siglo y los principios del XXI cuando se ha producido una nueva ruptura, aunque probablemente no tan dramática, protagonizada principalmente por autores europeos de novela policíaca. La innovación afecta a los dos elementos principales que conforman esta narrativa.

La estatura heroica del detective se reduce de forma significativa. Hemos pasado de caballero andante solitario a funcionario público. El culto al individualismo tan típicamente norteamericano ha dado paso a una voluntad de servicio basada en el trabajo en equipo. El escenario no son tanto las oscuras calles de la ciudad como los funcionales despachos de una comisaría de policía al servicio de los ciudadanos. Frente al eco mítico de nombres como Marlowe o Spade tenemos nombres más familiares como comisario Bordelli, inspector Wallander, sargento Bevilacqua o cabo Chamorro. Estos detectives europeos no parecen construidos tanto desde la larga tradición literaria como desde la normalidad cotidiana. Sus rasgos físicos y morales no son del trazo grueso de sus colegas norteamericanos, sino que se dejan entrever a través de la habilidad con la que llevan a cabo su trabajo.

La investigación se vuelve también más rutinaria. Ya no hay una búsqueda personal o un ansia de venganza. La violencia física es sustituida por la paciencia y el tesón. La investigación se dilata en el tiempo, semanas, meses o años y la casualidad y la suerte forman parte de ella. 
Es en este contexto en el que los recursos científicos del investigador se convierten en un personaje fundamental pero secundario. La ciencia forense es meramente otro elemento en la rutinaria y lenta maquinaria de la investigación. Una escena se ha convertido en arquetípica en estas novelas. El cadáver es hallado y al lugar del crimen acuden en primer lugar los policías, pero ninguno toca absolutamente nada hasta que llega el «coroner», el médico forense o «la científica». Este se inclina sobre el cuerpo e inicia una primera inspección ocular. El detective encargado del caso lanza una impaciente batería de preguntas sobre las causas y hora de la muerte, el experto se niega a ofrecer repuestas hasta haber llevado a cabo un trabajo más riguroso. El detective suplica algún dato, aunque sea aproximativo, y el experto a regañadientes lanza algunas hipótesis, las mínimas. La espera será lenta hasta que una llamada al despacho del policía le indique que los resultados de la autopsia están listos y puede pasar a recogerlos. Los datos no suelen ser concluyentes, no señalan con rigor inapelable hacia un culpable inequívoco, pero, al menos, suponen un punto de partida.

La figura del personaje que representa la ciencia en estas narrativas viene dibujada desde la más extrema peculiaridad hasta la más gris de las normalidades. En la primera novela de la doctora Kay Scarpetta, creada por Patricia D. Cornwell, la nueva y profesional «examinadora médica» recuerda los ya legendarios comportamientos de su antecesor, un homófobo radical que llegaba al lugar del crimen masticando su almuerzo, que nunca se ponía guantes durante su trabajo y que comía galletitas saladas mientras practicaba una autopsia. En claro contraste, los médicos forenses que aparecen en esa nueva variante policíaca venida de los países escandinavos y que conocemos como «nordic noir» representan perfectamente esa imagen de funcionario callado, riguroso y formal que actúa ante el cadáver con toda sobriedad y profesionalidad:

La autopsia fue realizada por un catedrático de setenta años. Llegó en el tren nocturno de Estocolmo y parecía estar en plena forma. Estuvo trabajando ocho horas sin apenas interrupciones.

Luego entregó un informe preliminar que decía así: «Muerte por estrangulamiento asociada a violencia sexual extrema. Hemorragias internas severas» (Sjöwal y Wahlöl, 2007: 17-18).

Por otra parte, frente a estos personajes que avalan desde la sombra la labor del policía protagonista, nos encontramos con las grandes estrellas de la medicina forense, todos esos expertos altamente cualificados, verdaderos superhéroes de la ciencia, sobre los que recaerá todo el peso de la investiga- 
ción y de la historia. Son estas unas tramas donde a los elementos arquetípicos de la narrativa policial se les une, por una parte, toda una apabullante parafernalia de conocimientos científicos que, en principio, se quieren rigu$\operatorname{rosos}^{19} \mathrm{y}$, por otra, una explícita, y a veces morbosa, descripción de las consecuencias del crimen.

En un primer momento, como no podía ser de otra manera, nos encontramos con un crimen y con una escena del crimen. Puesto que lo que se va a poner a prueba no es tanto la mera excelencia deductiva o intuitiva del detective como su preparación técnica y profesional, el caso en cuestión ha de ser siempre espectacular y especialmente enrevesado. Por ejemplo, en Informe Brennan, la antropóloga forense Temperance Brennan se enfrenta a un terrible y sospechoso accidente aéreo donde «trozos de cuerpo y restos del aparato cubrían el paisaje como si fuesen desechos en un vertedero» (Reichs, 2001: 17). En la novela Port Mortuory de la autora más famosa y leída de este tipo de ficción, Patricia D. Cornwell, el cadáver de un joven, que en apariencia ha muerto de un ataque al corazón y que se encuentra en la «nevera» del $\mathrm{CFC}^{20}$ (Centro Forense de Cambridge), después de que se le haya practicado la autopsia, ha empezado a sangrar por la boca y la nariz «y hay casi un litro de sangre en la bolsa» (Cornwell, 2012: 17). Esta circunstancia de que el crimen haya de ser cada vez más sofisticado o sorprendente es lo que amenaza con minar ese rigor científico que los autores defienden y que los lectores pueden exigir a este tipo de historias. En su artículo «C.S.I: Realidad y ficción de la ciencia forense», Miguel Orós Murázabal, de la Escuela Judicial de Barcelona, afirma que el éxito inicial de esta propuesta televisiva hizo que «una vez agotados los guiones - muy realistas- del principio, se vieron en la necesidad de recurrir a la fantasía... transmitiendo así una imagen muy alejada de la realidad» (Orós, 2008: 179).

La naturaleza de los casos a los que han de enfrentarse estos no ya «detectives-científicos» como Holmes, sino «científicos-detectives», también suele conseguir toda una serie de efectos escabrosos, no aptos para todos los estómagos. Por ejemplo, la primera aventura del doctor David Hunter, «es-

19 El caso ya número 18 de la doctora Kay Scarpetta, Port Mortuary, incluye una nota para «mis lectores» en la que la autora advierte: «Si bien esta es una obra de ficción, no es ciencia-ficción. Los métodos médicos y forenses, las tecnologías y las armas que está a punto de conocer existen en la actualidad, incluso mientras lee este libro» (Cornwell, 2012: 4).

20 El uso de acrónimos en este tipo de novelas, sobre todo las norteamericanas, es agotador. En la novela de Kathy Reichs al lugar del siniestro acuden: «NTSB, FBI, SBI, FAA, ATF, CBS, ABC. Y, naturalmente, el CEO» (Reichs, 2008: 40). 
pecialista en antropología forense», creado por el británico Simon Beckett, comienza así:

El cuerpo humano empieza a descomponerse cuatro minutos después de la muerte. Lo que hasta entonces era un recipiente de vida atraviesa su última metamorfosis fagocitándose a sí mismo. Las células se disuelven. El tejido se vuelve líquido y después gas. Inanimado, el cuerpo se convierte en un inmóvil festín para otros organismos. Primero las bacterias, después los insectos. Moscas. Ponen huevos, que no tardan en abrirse (Beckett, 2010: 19).

Ahora ya dependerá de la avidez científica del lector seguir o no con la lectura para averiguar qué ocurre exactamente cuando esos huevos se abren.

\section{BREVE E IMPOSIBLE CONCLUSIÓN}

La narrativa policíaca lleva siendo durante muchos años el género popular más escrito y más leído. Es por ello que este artículo solo puede aspirar a mostrar un muy limitado recorrido sobre cómo la ciencia ha logrado condimentar las tramas policíacas de estas obras. Muchas novelas, historias, autores y personajes se nos han quedado fuera, no mencionar a los agentes del FBI Mulder y Scully de Expediente $X$ ha resultado especialmente doloroso. Pero, al menos, espero haber despertado la curiosidad del lector animándole a rescatar las viejas historias de detectives de la adolescencia o a descubrir nuevas tramas criminales. Y, aunque es probable que la bala de hielo no pueda existir y que no nos quede claro qué reactivo precipita la hemoglobina, lo realmente importante es que siga siendo un misterio por qué estas obras son capaces de seguir proporcionándonos tantas horas de placer y entretenimiento.

\section{REFERENCIAS BIBLIOGRÁFICAS}

BECKETT, Simon (2009). La química de la muerte. Barcelona: Random House/Mondadori.

CHANDLER, Raymond (2009). El sueño eterno. En Todo Marlowe. Barcelona: RBA.

CHESTERTON, G.K (1939). El candor del Padre Brown. Buenos Aires: Editorial Losada.

COLLINS, Max Allan (2002). CSI: Sin City. New York: Simon and Shuster. 
COMA, Javier (1982). La novela negra: Historia de la aplicación del realismo crítico a la novela policiaca norteamericana. Barcelona: El Viejo Topo.

CONAN DOYLE, Sir Arthur (1908). «El misterio de Lower Norwood». En La resurrección de Sherlock Holmes. Madrid: Editorial Española-Americana.

- (2009). Sherlock Holmes Anotado. Las novelas, Leslie S. Klinger (ed.). Madrid: Ediciones Akal.

CORNWELL, Patricia (1990). Post-Mortem. New York: Avon Books.

- (2012). Port Mortuary. Barcelona: RBA.

FREEMAN, Austin (1994). «A Wastrel's Romance». En The Mammoth Book of Golden Age Detective Stories, Marie Smith (ed.). London: Robinson Publishing.

- (2004). «The Project Gutenberg EBook of The Red Thumb Mark». http://www.gutenberg.org/ebooks/11128.

GABORIAU, Émile (1869). Monseiur Lecoq. http://es.feedbooks.com/ book/3729/monsieur-lecoq.

GEHERIN, David (1985). Private Eye: The Image in Fiction. New York: Frederick Ungar.

HAYCRAFT, Howard (1974). The Art of the Mystery Story. New York: Carroll and Graft Publishers.

ORCZY, Baronesa de (1967). «El misterio de Dublín». En Antología de cuentos policiales, Javier Lasso de la Vega (ed.). Barcelona: Editorial Labor.

ORÓS MURAZABAL, Miguel (2008). «C.S.I.: Realidad y ficción en la ciencia forense». En Palabras que matan. Asesinos y violencia en la ficción criminal, Àlex Martín y Javier Sánchez (eds.). Almuzara.

POE, Edgar Allan (1959). «El doble asesinato de la calle Morgue». En Narraciones extraordinarias. Barcelona: Editorial Juventud.

REEVE, Arthur B. (1994). «Spontaneous Combustion». En The Mammoth Book of Goden Age Detective Stories, Marie Smith (ed.). London: Robinson Publishing.

REICHS, Kathy (2001). Informe Brennan. Barcelona: RBA.

SJÖWALL, Maj y WAHLÖ, Per (2007). Roseanna. Barcelona: RBA. 
SMITH, Marie (1994). The Mammoth Book of Golden Age Detective Stories. Victorian and Edwardian Novels, Novellas, and Tales of Crime. London: Robinson Publishing.

Recibido el 30 de junio de 2013.

Aceptado el 19 de septiembre de 2013. 
